\title{
Facing Good and Evil: Early Brain Signatures of Affective Biographical Knowledge in Face Recognition
}

\author{
Rasha Abdel Rahman \\ Humboldt-Universität zu Berlin
}

\begin{abstract}
Extracting meaning from faces to understand other people's mental states and intentions, and to quickly adjust our actions accordingly, is a vital aspect of our social interactions. However, not all emotionally relevant attributes of a person are directly observable from facial features or expressions. In this study event-related brain potentials were used to investigate the effects of affective information about a person's biography that cannot be derived from the visual appearance of the face. Faces of well-known and initially unfamiliar persons with neutral expressions were associated with negative, positive or neutral biographical information. For well-known faces, early event-related brain potential (ERP) modulations induced by emotional knowledge, their scalp topographies and time course strongly resemble the effects frequently reported for emotional facial expressions even though here, access to stored semantic knowledge is required. These results demonstrate that visually opaque affective knowledge is extracted at high speed and modulates sensory processing in the visual cortex.
\end{abstract}

keywords: face recognition, knowledge, emotion, familiarity

Inferences about other people's mental states, feelings and intentions are a core aspect of social interactions, guiding our actions and social behavior (Todorov, Said, \& Verosky, in press). Human faces, and, in particular, facial expressions, provide a rich source of information for such inferences. A smiling face can make us happy in an instant, an angry face rapidly signals potential danger to us, capturing our attention within a fraction of a second, and triggering adaptive responses of defense or escape (e.g., Adolphs, 2002; Holmes, Vuilleumier, \& Eimer, 2003; Öhman, Lundqvist, \& Esteves, 2001; Pessoa, McKenna, Gutierrez, \& Ungerleider, 2002; Schupp, Flaisch, Stockburger, \& Junghöfer, 2006).

However, not all emotionally relevant attributes of a person are directly observable. In contrast to the dynamic affective states reflected in facial expressions, emotionally significant internal information about a person's character, attitudes or good and evil deeds cannot be derived directly from the visual appearance of the face (but see Todorov, in press). Nevertheless, such visually opaque affective factors are intrinsically important: A person exhibiting a neutral facial expression may be known as a serial killer on the run, a piece of information that directly bears on our affect and motivational systems, signaling potential threat just as immanently as an angry facial expression does. Yet, in contrast to the well-investigated processing of facial expressions, surprisingly little is known about how and pre-

This article was published Online First August 22, 2011.

Rasha Abdel Rahman, Department of Psychology, HumboldtUniversität zu Berlin, Berlin, Germany.

This research was supported by grants from the German Research Foundation, $\mathrm{AB} 277$ - 1, 4 and 5, to Rasha Abdel Rahman. I thank Julia Junker, Kerstin Unger, Rainer Kniesche, and Thomas Pinkpank for assistance with the experiments, and Werner Sommer and Annekathrin Schacht for valuable comments on the manuscript.

Correspondence concerning this article should be addressed to Rasha Abdel Rahman, Humboldt-Universität zu Berlin, Rudower Chaussee 18, 12489 Berlin, Germany. E-mail: rasha.abdel.rahman@hu-berlin.de cisely when the brain responds to knowledge-based and unobservable internal affective attributes of persons.

Research in social cognition on affective categorization and learning suggests that associations of persons with trait and personality impressions are formed rapidly and require only minimal information about people's behaviors (e.g., Croft et al., 2010; Todorov \& Olson, 2008). Stable learning effects about the positive or negative value of unfamiliar people can be formed on the basis of sparse behavioral information, for example, that the person hit a small child (Bliss-Moreau, Barrett, \& Wright, 2008), and the spontaneous retrieval of such newly acquired affective person knowledge is reflected in the activation of neural regions associated with social cognition and emotion (Todorov, Gobbini, Evans, \& Haby, 2007).

Although these findings demonstrate strong and robust influences of affective knowledge on how we implicitly and explicitly evaluate other persons, the temporal dynamics of knowledge-based emotion effects and their interplay with perceptual aspects of face processing remain largely unknown. The present study focuses on a temporal and functional characterization of affective biographical knowledge effects in face recognition. The high temporal resolution of event-related brain potentials (ERPs) was exploited to investigate how the brain responds to faces associated with affective biographical knowledge, how rapidly affective knowledge is extracted, and whether affective knowledge modulates sensory processes, as demonstrated for affective stimuli such as pictures of mutilations and threat (Lang, Bradley, \& Cuthbert, 1995; Schupp, Junghöfer, Weike, \& Hamm, 2003), but also for facial expressions (Schupp et al., 2004). Long-term affective knowledge effects associated with well-known faces were contrasted with those induced by newly acquired knowledge about initially unfamiliar persons.

Faces of well-known and initially unfamiliar persons with neutral expressions were associated with emotionally negative, positive or comparatively neutral biographical information in a learn- 
ing session (cf. Appendix II). The affective or neutral biographical information about well-known persons (cf. Appendix I) was refreshed because not all well-known persons may be familiar to all participants. Furthermore, well-known persons may not always be recognizable based on photographs of their faces. The brain's response to the faces was measured two to three days after learning with ERPs in tasks that did not require the retrieval of the affective biographical knowledge.

Analyses focused on two distinct ERP components that are associated with the processing of emotional stimuli. Starting at around 150 $\mathrm{ms}$, a relative negative deflection at occipito-temporal sites is induced by emotional compared to neutral stimuli that reaches its maximum at about 200 to $300 \mathrm{~ms}$. This early posterior negativity (EPN) is assumed to be associated with early reflexive effects of emotion, reflecting attention to and enhanced perceptual processing of affective stimuli (e.g., Junghöfer, Bradley, Elbert, \& Lang, 2001; Kissler, Herbert, Peyk, \& Junghöfer, 2007; Schupp et al., 2003). At later stages emotional factors are associated with an enhanced positivity (late positive potential, LPP) over centro-parietal regions at around 400 to $600 \mathrm{~ms}$ (e.g., Cacioppo, Crites, Berntson, \& Coles, 1993; Cuthbert, Schupp, Bradley, Birbaumer, \& Lang, 2000). This late effect is assumed to reflect sustained and more elaborative processing of the intrinsic relevance of emotional stimuli. Both, early EPN and later LPP modulations have been demonstrated in response to faces with emotional relative to neutral expressions (e.g., Schacht \& Sommer, 2009; Schupp et al., 2004).

Given the fast ERP responses to affective stimuli and facial expressions, which predictions can be derived for the time course of the effects of affective biographical person knowledge? Recent research suggests that semantic factors can affect the processing of visual stimuli at very early points in time. Thus, basic semantic category information is extracted very rapidly (Grill-Spector \& Kanwisher, 2005; Thorpe, Fize, \& Marlot, 1996), and conceptual knowledge may even penetrate early stages of visual perception (e.g., Abdel Rahman \& Sommer, 2008; Lupyan, Thompson-Schill, \& Swingley, 2010). Of particular importance for the present study, attitudes and subjective affective valence associated with familiar faces and objects seem to be formed fast and automatically (Cacioppo et al., 1993; Cunningham, Johnson, Gatenby, Gore, \& Banaji, 2003; Cunningham \& Zelazo, 2007; Stone \& Valentine, 2004). In fact, valence, arousal and preference ratings on faces vary with the affective content of learned fictitious biographies even when the faces are not successfully recognized, as shown in patients with Alzheimer's disease (Blessing, Keil, Linden, Heim, \& Ray, 2006). Together, these findings suggest that affective biographical knowledge may not only modulate post-perceptual evaluative judgments but may already exert an influence on perceptual stages of face processing.

\section{Method}

\section{Participants}

Thirty right-handed native German speakers (17 women; mean age $=25$ years; range of $18-32$ ) participated in the experiment. Informed consent was obtained before the experiment.

\section{Materials}

Picture stimuli consisted of grayscale photographs of 24 wellknown (cf. Appendix I) and 36 unfamiliar male and female faces with neutral facial expressions. Photographs were taken from frontal views and were edited for homogeneity of all features outside of the face and a light blue background color, and scaled to $2.7 \times 3.5 \mathrm{~cm}$. For all unfamiliar faces spoken stories were recorded that contained biographical information about fictitious persons with neutral, emotionally positive or negative contents (mean durations: $62.5,62$, and $61.5 \mathrm{~s}$, respectively). In addition, spoken stories containing biographical facts of emotionally neutral, positive or negative value were recorded for all well-known faces (mean durations: 61.5, 62, and 62s, respectively; for examples, see Appendix II).

To exclude the possibility that any effects observed for wellknown faces are caused by subtle differences in facial expressions, an additional valence rating on the expressions of the 24 wellknown faces, was conducted with a different group of participants $(N=20)$. Facial expressions were rated on a 5-point scale from pleasant to unpleasant, analogously to the Self-Assessment Manikin (SAM; Lang, 1980; Bradley \& Lang, 1994). Participants were instructed to focus exclusively on the expressions of the faces. Additionally, they indicated whether the depicted person was familiar or unfamiliar to them (to avoid false negatives, 24 unfamiliar filler faces were presented together with the well-known faces). Across participants, $58.6 \%$ of the well-known faces were classified as familiar [63, 68, and $44 \%$ in the negative, positive and neutral condition, respectively; $F(2,38)=22.7 ; p<.001 ; \eta^{2}=$ $.54]$, and only two faces were identified by all participants.

The valence ratings of facial expressions did not only vary as a function of the affective biographical knowledge, $F(2,38)=22.0$; $p<.001, \eta^{2}=.53$, but also as a function of familiarity, $F(1,19)=$ 8.4; $p<.01, \eta^{2}=.30$. Whereas expressions of faces that were familiar to the individual participants were classified as more pleasant in the positive and more unpleasant in the negative relative to the neutral affective knowledge condition, $F(2,38)=$ 23.1; $p<.001, \eta^{2}=.54$, no differences were found for those faces that were classified as unfamiliar, $F(2,38)=2.3 ; p=.11, \eta^{2}=$ .11 . This was confirmed by a significant interaction of biographical knowledge and familiarity, $F(2,38)=5.1 ; p<.05, \eta^{2}=.21$. Thus, the very same faces are perceived as depicting an affective or neutral expression, depending on their familiarity. Because no valence differences were observed for faces classified as unfamiliar, differential facial expressions are unlikely a major confounding factor. The implications of the interplay between familiarity and the perception of facial expressions are discussed together with the ERP results in the discussion.

\section{Procedure}

The learning session consisted of two parts. In the first part, participants were familiarized with all unfamiliar faces and learned the later task-relevant information (names and nationalities). In the second part the unfamiliar faces were presented on the screen while participants listened to short stories describing fictitious biographical details about the persons. The stories contained either emotionally neutral information or emotional information of positive or negative valence. The assignment of the faces to stories 
with neutral, positive, or negative contents was counterbalanced across participants. All stories were presented three times in random order. Subsequently, the well-known faces were presented on the screen once, and participants listened to short stories describing biographical facts with neutral, positive, or negative contents about the persons. This was done to ensure that the critical biographical information was available.

The test session took place two to three days after learning and involved three tasks, none of which required the retrieval of the affective biographical knowledge. In the familiarity task participants classified all faces as well-known or newly learned by button presses. In the semantic task participants named the nationality of the faces, and in the speech production task the names were produced. Tasks alternated block-wise in counterbalanced order. All well-known and newly learned faces were presented three times within each task in random alternation.

A trial began with a fixation cross displayed in the center of a light gray screen for $0.5 \mathrm{~s}$, followed by a photograph which disappeared with the response or after $3 \mathrm{~s}$. One second later the next trial began. Participants were instructed to perform each task as fast and accurately as possible.

Before the learning session and after the test session participants performed paper-and-pencil sympathy ratings on all faces. They were instructed to indicate how likable they find each depicted person on a 5-point scale ranging from -2 (very unlikable person) to 2 (very likable person).

\section{Data Recording and Analysis}

The electroencephalogram (EEG) was recorded with $\mathrm{Ag} / \mathrm{AgCl}$ electrodes from 56 sites according to the extended 10-20 system, referenced to the left mastoid, and at a sampling rate of $500 \mathrm{~Hz}$ (bandpass $0.032-70 \mathrm{~Hz}$ ). The horizontal and vertical electrooculograms were measured with external electrodes attached to the left and right canthi of both eyes and beneath and above the left eye. Electrode impedance was kept below $5 \mathrm{k} \Omega$. A short calibration procedure was used to obtain ERP topographies for prototypical eye movements, used to correct for eye movement artifacts. Offline, the continuous EEG was transformed to average reference and low-pass filtered at $30 \mathrm{~Hz}$. Eye movement artifacts were removed with a spatiotemporal dipole modeling procedure using BESA (Berg \& Scherg, 1991); remaining artifacts were eliminated with a semiautomatic artifact rejection procedure (amplitudes over $\pm 100 \mu \mathrm{V}$, changing more than $50 \mu \mathrm{V}$ between samples or more than $200 \mu \mathrm{V}$ within single epochs, or containing baseline drifts). Error- and artifact-free EEG data were segmented into epochs of $2.5 \mathrm{~s}$, starting $100 \mathrm{~ms}$ prior to picture onset, with a 100 ms prestimulus baseline interval.

Amplitude differences were assessed with repeated-measures analyses of variance (ANOVAs) with the factors familiarity (well-known vs. newly learned faces), task (familiarity classification, nationality, and name production), and emotional knowledge (neutral, positive, negative), interactions were followed up with separate ANOVAs. Huyhn-Feldt corrections were applied when appropriate. Based on reports in the literature on temporal and topographical distributions of emotion effects (e.g., Schupp et al., 2003) we focused on two regions of interest for the analyses of early effects of emotion in the EPN component (electrode sites: PO7, PO8, PO9, PO10, TP9, TP10) between 200 and $300 \mathrm{~ms}$ after stimulus onset, and later effects in the
LPP component (electrode sites: $\mathrm{Pz}, \mathrm{Cz}, \mathrm{C} 1, \mathrm{C} 2, \mathrm{CP} 1, \mathrm{CP} 2$ ) in two time windows between 400 and $600 \mathrm{~ms}$.

\section{Results}

\section{Sympathy Ratings Before and After Biographical Knowledge Acquisition}

As illustrated in Figure 1, newly learned faces were rated as more likable after than before knowledge acquisition when neutral or positive information was learned, $F(1,29)=33.8 ; p<.001$, $\eta^{2}=.53$, and $F(1,29)=30.6 ; p<.001, \eta^{2}=.51$, respectively, and rated as more dislikable when negative information was learned, $F(1,29)=54.2 ; p<.001, \eta^{2}=.65$. The same pattern was found for well-known faces. They were rated as more likable after than before knowledge acquisition when neutral or positive information was learned, $F(1,29)=5.7 ; p<.05, \eta^{2}=.16$, and $F(1,29)=26.2 ; p<.001, \eta^{2}=.47$, respectively, and rated as more dislikable when negative information was learned, $F(1$, 29) $=49.1 ; p<.001, \eta^{2}=.62$. Thus, affective biographical information modulated the sympathy ratings not only for initially unfamiliar but also for well-known faces. One reason for this might be that not all well-known faces were familiar to all participants before learning.

Before knowledge acquisition faces of well-known persons associated with neutral or positive information were rated as more likable than their initially unfamiliar counterparts, $F(1,29)=14.0$; $p<.001, \eta^{2}=.32$, and $F(1,29)=41.9 ; p<.001, \eta^{2}=.59$, respectively, and those associated with negative information were rated as more dislikable, $F(1,29)=16.8 ; p<.001, \eta^{2}=.36$. These differences strongly declined after knowledge acquisition and were present only in the positive, $F(1,29)=9.6 ; p<.01$, $\eta^{2}=.25$, but not in the negative and neutral conditions, $F \mathrm{~s}<3.4$. A detailed summary of all statistical effects, that are not directly relevant for the present purpose, can be found in Table 1 .

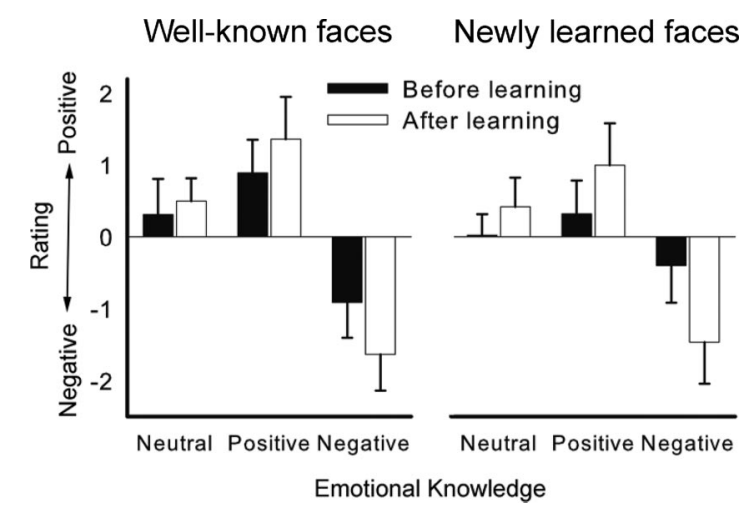

Figure 1. Results of the sympathy ratings for well-known (left) and newly learned faces (right) before and after learning. Faces associated with positive biographical information were rated as more likable before than after learning, and faces associated with negative information were rated as more dislikeable. Initial differences between the ratings for well-known and newly learned faces strongly declined after affective knowledge acquisition. Error bars depict standard errors of means. 
Table 1

Summary of the Statistical Analyses of the Sympathy Rating

\begin{tabular}{lccc}
\hline \multicolumn{1}{c}{ Source } & $d f$ & $F$ & $\eta^{2}$ \\
\hline Familiarity & 1.29 & $4.1^{*}$ & .12 \\
Pre/Post Knowledge acquisition & 1.29 & 0.1 & .00 \\
Knowledge condition & 2.58 & $276.1^{* * * *}$ & .90 \\
$\quad$ Familiarity $\times$ Pre/Post Knowledge & & & \\
$\quad$ acquisition & 1.29 & 0.2 & .00 \\
Familiarity $\times$ Knowledge condition & 2.58 & $34.9^{* * * *}$ & .54 \\
$\quad$ Knowledge condition $\times$ Pre/Post & & & \\
$\quad$ Knowledge acquisition & 2.58 & $70.9^{* * * *}$ & .54 \\
$\quad$ Familiarity $\times$ Knowledge condition $\times$ & & & \\
$\quad$ Pre/Post Knowledge acquisition & 2.58 & $7.2^{* * *}$ & .71 \\
\hline
\end{tabular}

${ }^{*} p<.05 .^{* * *} p<.01 .^{* * * *} p<.001$.

\section{Reaction Times and Error Rates}

Across well-known and newly learned faces reaction times were faster and error rates were lower in the negative relative to the neutral condition, $F(1,29)=48.5 ; p<.001, \eta^{2}=.62, F(1,29)=$ $11.3 ; p<.002, \eta^{2}=.28$, respectively, and in the negative relative to the positive condition, $F(1,29)=29.0 ; p<.001, \eta^{2}=.50$, and $F(1,29)=2.9 ; p=.09, \eta^{2}=.09$, respectively (cf. Figure 2), whereas the positive and neutral conditions did not differ, $F_{\mathrm{S}}<3$. A detailed summary of all statistical effects in behavioral data can be found in Tables 2 and 3.

\section{Event-Related Brain Potentials}

In the EPN time window an enhanced negativity as a function of affective biographical knowledge was found with a maximum at posterior sites between 200 and $300 \mathrm{~ms}, F(2,58)=24.7 ; p<.001$, $\eta^{2}=.46$ (see Figure 3). Emotional knowledge effects were not modulated by task, $F<0.5$. There was also a main effect of familiarity, $F(1,29)=83.7 ; p<.001 ; \eta^{2}=.74$, and familiarity strongly interacted with emotional knowledge, $F(2,58)=30.0$, $p<.001, \eta^{2}=.50$, confirming the visual impression that emotional modulations of the EPN amplitude are confined to wellknown faces. Thus, emotional knowledge effects were found for well-known faces for the comparison between the positive and neutral condition, $F(1,29)=68.4 p<.001, \eta^{2}=.70$, and for the comparison between the negative and neutral condition, $F(1$, $29)=41.5, p<.001, \eta^{2}=.58$. As depicted in Figure 3, affective

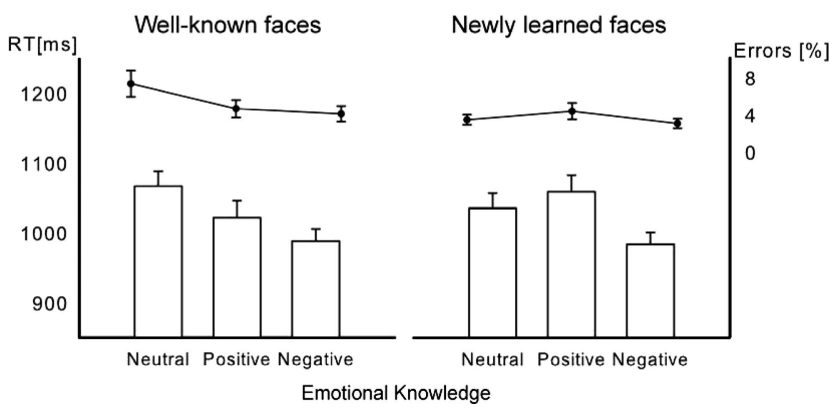

Figure 2. Behavioral results for well-known (left) and newly learned faces (right) as a function of the valence of the biographical knowledge. Error bars depict standard errors of means.
Table 2

Summary of the Statistical Analyses of Reaction Times

\begin{tabular}{lccl}
\hline \multicolumn{1}{c}{ Source } & $d f$ & $F$ & $\eta^{2}$ \\
\hline Familiarity & 1.29 & .0 & .0 \\
Task & 2.58 & $356.4^{* * * *}$ & .92 \\
Knowledge condition & 2.58 & $29.9^{* * * *}$ & .50 \\
Familiarity $\times$ Task & 2.58 & $10.3^{* * * *}$ & .26 \\
Familiarity $\times$ Knowledge condition & 2.58 & $7.5^{* * *}$ & .20 \\
Task $\times$ Knowledge condition & 4.116 & $17.8^{* * *}$ & .38 \\
Familiarity $\times$ Task $\times$ Knowledge condition & 4.116 & $2.7^{*}$ & .08 \\
\hline
\end{tabular}

${ }^{*} p<.05$. $^{* *} p<.01 .{ }^{* * *} p<.001$.

knowledge of negative value had a stronger effect than positive affective knowledge, $F(1,29)=24.2 ; p<.001, \eta^{2}=.45$.

To more precisely determine the onset of the EPN $t$-tests were calculated for each time point separately for each electrode of the EPN region of interest (significance criterion: $p<.05$ ). The onset was determined when at least 20 successive time points $(40 \mathrm{~ms})$ reached the significance criterion at all six electrodes. The negative and neutral conditions started to diverge at $182 \mathrm{~ms}$, the positive and neutral conditions started to diverge at $188 \mathrm{~ms} .{ }^{1}$ In contrast, for newly learned faces emotional knowledge had no effect on posterior electrodes between 200 and $300 \mathrm{~ms}, F(1,29)<1$.

As illustrated in Figure 3, emotional knowledge also elicited a later LPP effect with a central maximum between 400 and $600 \mathrm{~ms}$, $F(2,58)=16.5 ; p<.001 ; \eta^{2}=.36(400-500 \mathrm{~ms})$, and $F(2,58)=$ $15.4 ; p<.001 ; \eta^{2}=.34,(500-600 \mathrm{~ms})$, which was not modulated by task $(F \mathrm{~s}<2.1)$. There was a main effect of familiarity, $F(1,29)=39.2 ; p<.001, \eta^{2}=57,(400-500 \mathrm{~ms})$, and $F(1,29)=$ 59.1; $p<.001, \eta^{2}=67,(500-600 \mathrm{~ms})$, and familiarity interacted with emotional knowledge, $F(2,58)=19.7 ; p<.001, \eta^{2}=.40$, $(400-500 \mathrm{~ms})$, and $F(2,58)=5.6 ; p<.01, \eta^{2}=.16,(500-600$ $\mathrm{ms}$ ), reflecting stronger affective knowledge effects for wellknown than for newly learned faces.

Separate analyses revealed effects of emotional knowledge for well-known faces in the positive and negative conditions in both time windows, $F(1,29)=27.1 ; p<.001, \eta^{2}=.48$, (400-500 ms), and $F(1,29)=13.6 ; p<.001, \eta^{2}=.32(500-600 \mathrm{~ms})$, for the comparison positive versus neutral, and $F(1,29)=32.8 ; p<.001, \eta^{2}=.53$ $(400-500 \mathrm{~ms})$, and $F(1,29)=52.3 ; p<.001, \eta^{2}=.64(500-600$ $\mathrm{ms})$, for the comparison negative versus neutral, with a stronger LPP modulation in the negative compared to the positive condition, $F(1$, $29)=15.3, p<.001, \eta^{2}=.34(400-500 \mathrm{~ms})$, and $F(1,29)=6.3$, $p<.05, \eta^{2}=.17$ (500-600 ms).

Emotional knowledge modulated LPP amplitudes to newly learned faces between 500 and $600 \mathrm{~ms}$ only in the negative, $F(1$,

\footnotetext{
${ }^{1}$ In a time window slightly before the onset of the EPN (150 to $200 \mathrm{~ms}$ ) there was also an effect of familiarity at electrode sites P7/P8, where the N170 component was maximal, $F(1,29)=20.7 p<.001, \eta^{2}=.41$. The N170 is a face-sensitive component that reflects structural encoding and configural processing of faces. Because the N170 is typically regarded as reflecting processes that precede person identification and is typically not affected by familiarity (for recent reviews see Eimer, 2011; Schweinberger, 2011), this effect may be due to differences in physical stimulus attributes between the familiar and unfamiliar faces presented in the current study, and is therefore not further interpreted.
} 
Table 3

Summary of the Statistical Analyses of Error Rates

\begin{tabular}{llcl}
\hline \multicolumn{1}{c}{ Source } & \multicolumn{1}{c}{$d f$} & \multicolumn{1}{c}{$F$} & $\eta^{2}$ \\
\hline Familiarity & 1.29 & $3.4^{\circ}$ & .10 \\
Task & 2.58 & $11.5^{* * * *}$ & .28 \\
Knowledge condition & 2.58 & $5.8^{* * *}$ & .16 \\
Familiarity $\times$ Task & 2.58 & 1.8 & .06 \\
Familiarity $\times$ Knowledge condition & 2.58 & $7.7^{* *}$ & .21 \\
Task $\times$ Knowledge condition & 4.116 & $3.6^{* *}$ & .11 \\
Familiarity $\times$ Task $\times$ Knowledge condition & 4.116 & 1.1 & .03 \\
\hline
\end{tabular}

${ }^{\circ} p<.10 .{ }^{* *} p<.01 .^{* * *} p<.001$.

29) $=5.2 ; p<.05, \eta^{2}=.15$, but not in the positive condition, $F_{\mathrm{S}}<1$.

\section{Discussion}

Affective biographical knowledge elicited an enhanced late positive potential and, most important for the present purpose, an early posterior negativity with a classic time course and occipito- temporal topographical distribution, starting at about $180 \mathrm{~ms}$. EPN modulations in response to affective objects and scenes (Schupp et al., 2003), facial expressions (Schupp et al., 2004), words (e.g., Kissler et al., 2007; Schacht \& Sommer, 2009), and even hand gestures (Flaisch, Hacker, Renner, \& Schupp, 2010) have been interpreted to reflect facilitation of sensory processing in the visual cortex. Thus, our findings suggest that affective person knowledge is extracted rapidly, and that this knowledge has an influence not only on post-perceptual evaluative judgments about how likable or unlikable the person is experienced, but also on how we perceive his or her face.

Both, early EPN and late LPP effects were more pronounced for negative compared to positive biographical knowledge, and both effects were strongly modulated by familiarity. In particular, the EPN modulation was present only for well-known faces that were familiar, at least in many cases, already prior to the experiment. Moreover, a direct comparison of familiarity and affective knowledge effects (as depicted in Figure 4) suggests that both factors are closely linked and appear to induce continuous ERP modulations from initially unfamiliar faces over well-known faces associated with comparatively neutral information to those associated with
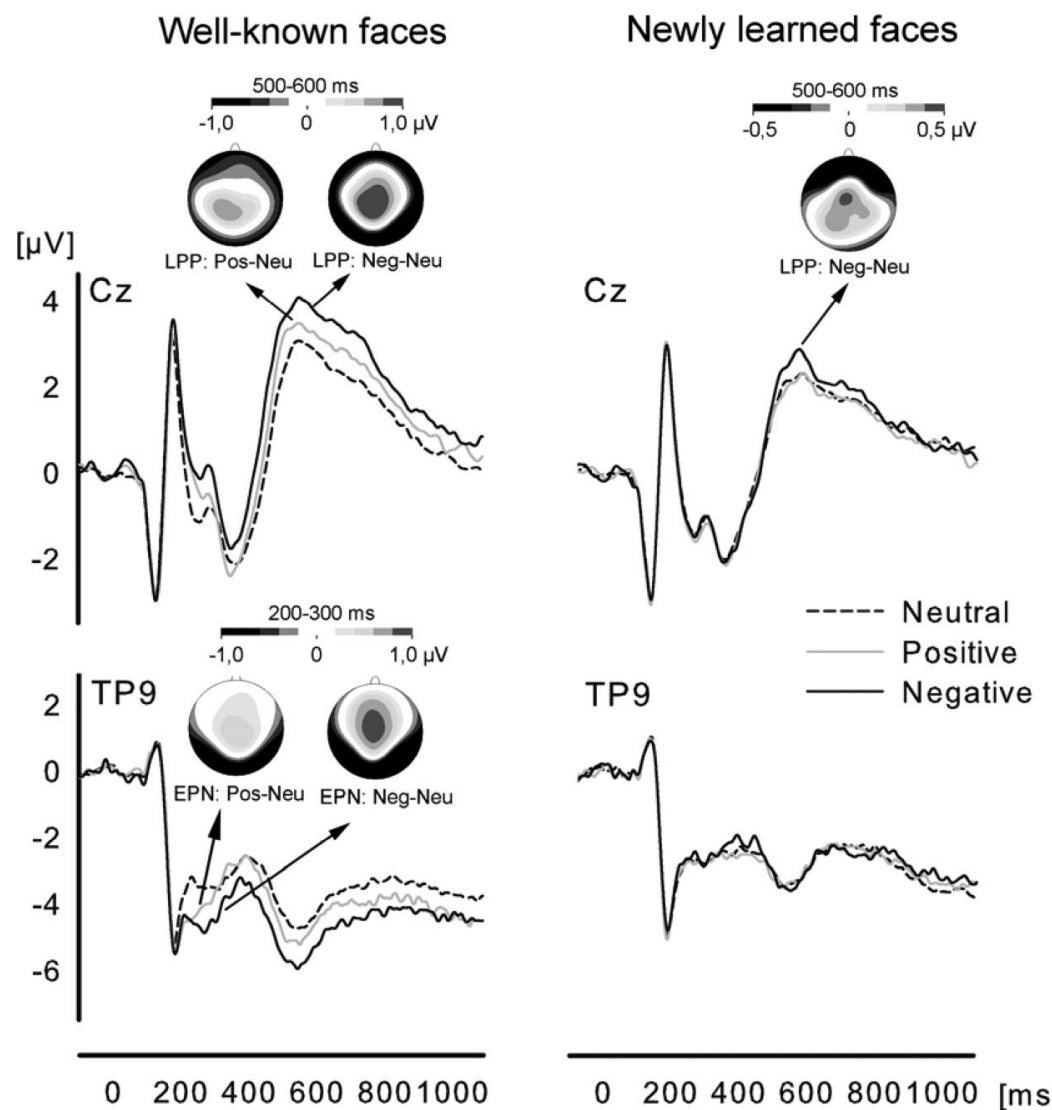

\section{0 [ms]}

Figure 3. Grand average event-related brain potentials show the time course of affective biographical knowledge effects on the processing of well-known (left) and newly learned faces (right). Top: Post-perceptual and comparatively late affective knowledge effects in the LPP component, shown here at a central site $(\mathrm{Cz})$, are present for and well-known and newly learned faces. Bottom: Affective knowledge had a strong effect on the EPN component, shown here at a posterior site (TP9), for well-known faces but no effect for newly learned faces. Shown above the waveforms are the scalp distributions of the differences between the negative and neutral and positive and neutral conditions in the EPN and LPP time windows. 
a

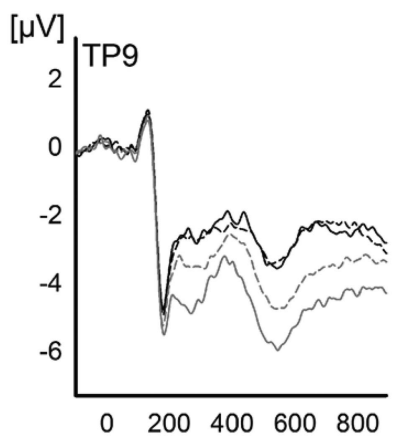

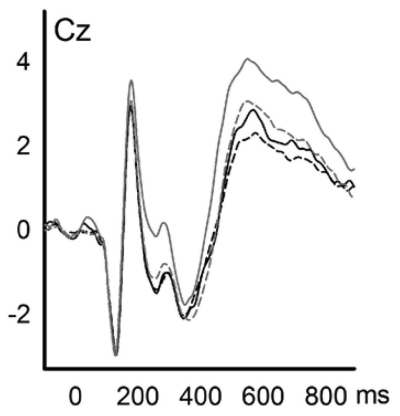

b

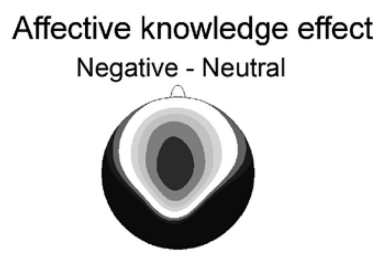

Familiarity effect

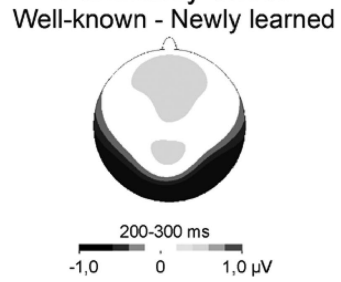

Figure 4. Direct comparison of familiarity and affective biographical knowledge effects. The waveforms in (a) show the grand average ERPs in the EPN and LPP time window at electrode sites TP9 and Cz. Shown in (b) are the topographical distributions of negative affective knowledge and familiarity effects between 200 and 300 ms.

affective biographical knowledge. The present finding of an enhanced posterior negativity for well-known compared to initially unfamiliar faces between 200 and $300 \mathrm{~ms}$ (cf. Figure 4) corresponds with many reports of the N250 as an index of face familiarity (e.g., Schweinberger, Pfütze, \& Sommer, 1995; Tanaka, Curran, Porterfield, \& Collins, 2006). This component reflects different levels of familiarity, with increasing amplitudes from unfamiliar over famous to personally familiar faces (Herzmann, Schweinberger, Sommer, \& Jentzsch, 2004). The tight relationship between familiarity and affective knowledge observed here may suggest that the N250's sensitivity to different levels of familiarity may in part reflect associated differences in the affective value of familiar persons. For instance, personally familiar faces have a higher personal relevance, and should thus evoke stronger affective responses, than the faces of famous persons known, for instance, from news reports. However, more work is needed to establish the impact of affective factors on N250 amplitudes.

Based on the results of the additional familiarity and emotional expression rating (see Materials) it seems unlikely that expression differences are a major source of the EPN effects observed for well-known faces. The absence of valence differences in the expression ratings of faces classified as unfamiliar suggests that the EPN effects are induced by the affective knowledge, and not by subtle differences in facial expressions. Such visual differences should affect the expression ratings irrespective of the familiarity of the face.

In line with the EPN effects, the expression rating suggests that facial expressions cannot be viewed independently of the affective biographical knowledge associated with a person. Whether we perceive a facial expression as negative, positive or neutral seems to be determined, at least in part, by the valence of our knowledge about the person. Hence, our findings provide additional support for the interplay of familiarity and emotional expression perception in face recognition (e.g., Wild-Wall, Dimigen \& Sommer, 2008). Some studies have demonstrated that emotional expressions may facilitate identification (e.g., Baudouin, Gilibert, Sansone, \& Tiberghien, 2000). The present findings complement this research by suggesting that affective knowledge exerts a bias on the perception of facial expressions.

In contrast to the absence of affective knowledge effects for initially unfamiliar faces in the EPN, a small but reliable effect was found in the LPP component. Likewise, the sympathy ratings demonstrate that initially unfamiliar faces were judged as more likable or dislikable after knowledge acquisition, depending on the valence of the acquired knowledge. Initial differences between the sympathy ratings for well-known and unfamiliar faces before knowledge acquisition strongly declined thereafter (cf. Figure 1).

The dissociation between well-known and initially unfamiliar faces in the EPN, together with the presence of affective knowledge effects for initially unfamiliar faces in the LPP and in the sympathy ratings, suggest that newly acquired affective knowledge has an influence on post-perceptual evaluative processes but does not seem to affect earlier perceptual aspects of face processing. This observation is in line with a recent report on relatively late influences of newly acquired trustworthiness information. Rudoy and Paller (2009) have demonstrated that trustworthiness ratings were influenced by the extraction of relevant information from facial features earlier than by the retrieval of learned verbal personality trait information. The late effect of the learned information was reflected in ERPs as a parietal maximum at about 800 $1000 \mathrm{~ms}$. Even though the late affective knowledge effects for initially unfamiliar faces reported here had an earlier onset, they may reflect similar memory-based effects of newly acquired affective information.

How can we account for the observation that only affective biographical knowledge that is associated with well-known faces-and that has been stored in long-term memory for a comparatively long time-has an influence on sensory processes? It is proposed here that the interplay of knowledge- and perception-based affective face processing is the result of our past experiences with, and the repeated exposure to, faces that provoke strong affective responses. For instance, repeated encounters with photographs depicting a dictator in news reports, accompanied by reports of 
brutality and oppression, may induce strong affective responses that in turn shape how we perceive the face in the future.

In line with a recent hypothesis on the role of affect-driven predictions during object perception by Barrett and Bar (2009), one may suggest that these past encounters with their accompanying affective physical reactions shape the visual perception of the faces. Specifically, the authors propose that ongoing object perception incorporates a reenactment of our affective responses to the object in the past (for a related proposal see Barsalou, 1999). Based on quickly available low spatial frequency visual information and these rapid bodily reactions, orbitofrontal brain structures generate fast predictions on the affective value or relevance of the visual input. These affective predictions support early visual analyses.

Thus, from this perspective, affective biographical knowledge is represented by our past emotional responses to the faces, and is, as such, an integral part of the perception process, supporting visual analysis and identification. Future research will have to determine the precise conditions that may drive such affective learning effects on the perception of initially unfamiliar faces. For instance, a repeated confrontation with initially unfamiliar faces and associated affective information (or information related to personal trustworthiness; Rudoy \& Paller, 2009, see discussion above) over a more extended period of time as realized here may induce EPN effects comparable to those observed here for well-known faces.

To summarize, the present findings demonstrate that face perception is strongly affected by our knowledge about the positive or negative value of a person, derived from affective biographical information that cannot be inferred directly from the visual appearance of the face.

\section{References}

Abdel Rahman, R., \& Sommer, W. (2008). Seeing what we know and understand: How knowledge shapes perception. Psychonomic Bulletin \& Review 15, 1055-1063.

Adolphs, R. (2002). Recognizing emotion from facial expressions: Psychological and neurological mechanisms. Behavioral and Cognitive Neuroscience Reviews, 1, 21-62.

Barrett, L. F., \& Bar, M. (2009). See it with feeling: Affective predictions in the human brain. Philosophical Transactions of the Royal Society B: Biological Sciences, 364, 1325-1334.

Barsalou, L. W., \& Perceptual symbol systems. (1999). Behavioral and Brain Sciences, 22, 577-660.

Baudouin, J. Y., Gilibert, D., Sansone, S., \& Tiberghien, G. (2000). When the smile is a cue to familiarity. Memory, 8, 285-292.

Berg, P., \& Scherg, M. (1991). Dipole modelling of eye activity and its application to the removal of eye artefacts from the EEG and MEG. Clinical Physiology and Physiological Measurements, 12, 49-54.

Blessing, A., Keil, A., Linden, D. E. J., Heim, S., \& Ray, W. J. (2006). Acquisition of affective dispositions in dementia patients. Neuropsychologia, 44, 2366-2373.

Bliss-Moreau, E., Barrett, L. F., \& Wright, C. I. (2008). Individual differences in learning the affective value of others under minimal conditions. Emotion, 8, 479-493.

Bradley, M. M., \& Lang, P. J. (1994). Measuring emotion: The selfassessment manikin and the semantic differential. Journal of Behavioural Therapy and Experimental Psychiatry, 25, 49-59.

Cacioppo, J. T., Crites, S. L., Jr., Berntson, G. G., \& Coles, M. G. H. (1993). If attitudes affect how stimuli are processed, should they not affect the event-related brain potential? Psychological Science, 4, 108-112.

Croft, K. E., Duff, M. C., Kovach, C. K., Anderson, S. W., Adolphs, R., \&
Tranel, D. (2010). Detestable or marvelous? Neuroanatomical correlates of character judgments. Neuropsychologia, 48, 789-801.

Cunningham, W., \& Zelazo, P. D. (2007). Attitudes and evaluation: A social cognitive neuroscience perspective. Trends in Cognitive Sciences, 11, 97-104.

Cunningham, W. A., Johnson, M. K., Gatenby, J. C., Gore, J. C., \& Banaji, M. R. (2003). Neural components of social evaluation. Journal of Personality and Social Psychology, 85, 639-649.

Cuthbert, B. N., Schupp, H. T., Bradley, M. M., Birbaumer, N., \& Lang, P. J. (2000). Brain potentials in affective picture processing: Covariation with autonomic arousal and affective report, Biological Psychology, 52, 95-111.

Eimer, M. (2011). The face-sensitive N170 component of the event-related brain potential. In A. J. Calder, G. Rhodes, M. H. Johnson, \& J. V. Haxby (Eds.), The handbook of face perception. New York: Oxford University Press.

Flaisch, T., Hacker, F., Renner, B., \& Schupp, H. T. (2011). Emotion and the processing of symbolic gestures: An event-related brain potential study. Social, Cognitive and Affective Neuroscience, 6, 109-118.

Grill-Spector, K., \& Kanwisher, N. (2005). Visual recognition: As soon as you know it is there, you know what it is. Psychological Science, 16, 152-160.

Herzmann, G., Schweinberger, S. R., Sommer, W., \& Jentzsch, I. (2004). What's special about personally familiar faces? A multimodal approach. Psychophysiology, 41, 688-701.

Holmes, A., Vuilleumier, P., \& Eimer, M. (2003). The processing of emotional facial expression is gated by spatial attention: Evidence from event-related brain potentials. Cognitive Brain Research, 16, 174-184.

Junghöfer, M., Bradley, M. M., Elbert, T. R., \& Lang, P. J. (2001). Fleeting images: A new look at early emotion discrimination, Psychophysiology, $38,175-178$.

Kissler, J., Herbert, C., Peyk, P., \& Junghofer, M. (2007). Buzzwords: Early cortical responses to emotional words during reading. Psychological Science, 18, 475-480.

Lang, P. J. (1980). Behavioral treatment and bio-behavioral assessment: Computer applications. In: J. B. Sidowski, J. H. Johnson, \& T. A Williams (Eds.), Technology in mental health care delivery systems (pp. 119-137). Norwood, NJ: Ablex.

Lang, P. J., Bradley, M., \& Cuthbert, B. (1995). International Affective Picture System: Technical manual and affective ratings. Gainesville FL: Center for Research in Psychophysiology, University of Florida.

Lupyan, G., Sharon, L., Thompson-Schill, S. L., \& Swingley, D. (2010). Conceptual penetration of visual processing. Psychological Science, 21, 682-691.

Öhman, A., Lundqvist, D., \& Esteves, F. (2001). The face in the crowd revisited: A threat advantage with schematic stimuli. Journal of Personality and Social Psychology, 80, 381-396.

Pessoa, L., McKenna, M., Gutierrez, E., \& Ungerleider, L. G. (2002). Neural processing of emotional faces requires attention. Proceedings of the National Academy of Science, USA, 99, 11458-11463.

Rudoy, J. D., \& Paller, K. A. (2009). Who can you trust? Behavioral and neural differences between perceptual and memory-based influences. Frontiers in Human Neuroscience, 3, 16.

Schacht, A., \& Sommer, W. (2009). Emotions in word and face processing: Early and late cortical responses. Brain \& Cognition, 69, 538-550.

Schupp, H. T., Flaisch, T., Stockburger, J., \& Junghöfer, M. (2006). Emotion and attention: Event-related brain potential studies. In Understanding emotions: Progress in brain research (Vol. 156).

Schupp, H. T., Junghöfer, M., Weike, A. I., \& Hamm, A. O. (2003) Emotional facilitation of sensory processing in the visual cortex. Psychological Science, 14, 7-13.

Schupp, H. T., Öhman, A., Junghöfer, M., Weike, A. I., Stockburger, J., \& Hamm, A. O. (2004). The facilitated processing of threatening faces: An ERP analysis. Emotion, 4, 189-200.

Schweinberger, S. R. (2011). Neurophysiological correlates of face recognition. In A. J. Calder, G. Rhodes, M. H. Johnson, \& J. V. Haxby (Eds.), The handbook of face perception. New York: Oxford University Press. 
Schweinberger, S. R., Pfütze, E.-M., \& Sommer, W. (1995). Repetition priming and associative priming of face recognition: Evidence from event-related potentials. Journal of Experimental Psychology: Learning, Memory, and Cognition, 21, 722-736.

Stone, A. M., \& Valentine, T. (2004). Better the devil you know? Nonconscious processing of identity and affect of famous faces. Psychonomic Bulletin \& Review, 11, 469-474.

Tanaka, J. W., Curran, T., Porterfield, A. L., \& Collins, D. (2006). Activation of preexisting and acquired face representations: The N250 event-related potential as an index of face familiarity. Journal of Cognitive Neuroscience, 18, 1488-1497.

Thorpe, S., Fize, D., \& Marlot, C. (1996). Speed of processing in the human visual system. Nature, 381, 520-522.

Todorov, A. (in press). Evaluating faces on social dimensions. In A. Todorov, S. T. Fiske, \& D. Prentice (Eds.), Social Neuroscience: To- ward Understanding the Underpinnings of the Social Mind. New York: Oxford University Press.

Todorov, A., Gobbini, M. I., Evans, K. K., \& Haxby, J. V. (2007) Spontaneous retrieval of affective person knowledge in face perception. Neuropsychologia, 45, 163-173.

Todorov, A., \& Olson, I. (2008). Robust learning of affective trait associations with faces when the hippocampus is damaged but not when the amygdala and temporal pole are damaged. Social, Cognitive, \& Affective Neuroscience, 3, 195-203.

Todorov, A., Said, C. P., \& Verosky, S. C. (in press). Personality impressions from facial appearance. In A. Calder, J. V. Haxby, M. Johnson, \& G. Rhodes (Eds.), Handbook of face perception. New York: Oxford University Press.

Wild-Wall, N., Dimigen, O., \& Sommer, W. (2008). Interaction of facial expressions and familiarity: ERP evidence. Biological Psychology, 77, 138-149.

\section{Appendix I}

\section{Well-Known Faces Associated With Negative, Positive and Comparatively Neutral Biographical Information Presented in the Experiment}

\section{Negative Condition}

Joseph Stalin

Marc Dutroux

Adolf Hitler

Idi Amin

Slobodan Milošević

Saddam Hussein

\section{Positive Condition}

Mahatma Gandhi

Mother Teresa

Dalai Lama

Nelson Mandela

Martin Luther King
Sophie Scholl

\section{Neutral Condition}

Anne Will
Günter Verheugen
Max Frisch
Mette-Marit of Norway
Javier Solana
Alan Greenspan
Jamie Oliver
Pablo Picasso
Romano Prodi
Maria Callas
Christo
Coco Chanel

\section{Appendix II}

Examples of Short Stories Containing Biographical Information of Negative, Positive, and Neutral Value, English Translations

\section{Well-Known, Negative}

The dictatorial politician Stalin was the supreme ruler of the Soviet Union from 1922 until 1953. His near absolute power was based on a regime of terror. He attacked his political opponents in a series of perges, resulting in the execution of thousands and the exile of millions to the gulag system of labor camps. Stalin's forced collectivization of agriculture led to a big famine that caused millions of deaths.

\section{Well-Known, Positive}

Gandhi was a pacifist, human rights activist, and the political and spiritual leader of the Indian independence movement. His concept of nonviolent resistance and peaceful noncooperation with the British attracted millions of followers and helped free India from British rule in 1947. The Indian people called Gandhi Mahatma, the Hindu term for Great Soul. He is officially honored as the Father of the Nation. 


\section{Well-Known, Neutral}

Anne Will, born in 1966 in cologne, is a political scientist and a journalist. She finished her studies of history, politics, and anglistics in 1990. Working as a sports news presenter, she became famous in 1999. During the Summer Olympics in 2000 she presented a variety of live sports shows from Sydney, Australia on ARD. Since 2001 she presents the late night news magazine Tagesthemen in alternation with Ulrich Wickert.

\section{Fictitious, Negative}

This man has attacked and robbed numerous elderly people. He pretends to assist with carrying shopping bags or forces his way in the apartments under false pretences. Once alone with his victims, he acts with indescribable brutality. He bashed the head of a 90 -year-old woman in. Another victim suffered multiple knife wounds and bled to death while he was searching for valuable items in her apartment.

\section{Fictitious, Positive}

This woman has been living in Africa for several years, where she cares affectionately for the poorest of the poor. She helps providing food, housing and education. She cares for the children with warmth and affection and takes care of the sick and dying in a home for people with HIV and leprosy. Without much public attention for her humanitarian work she continues her tireless efforts on behalf of the poor and helpless.

\section{Fictitious, Neutral}

This woman is in her forties and a high school teacher. She teaches the ancient languages Latin and Greek. In addition to languages she has studied ancient history with a special interest in the study of Greek and Roman religion. She frequently organizes visits to museums of history and history of art for interested students. Additionally, she has organized several school trips to Rome and Athens.

\section{New Journal Announcement: Couple and Family Psychology: Research and Practice}

The Publications and Communications Board of the American Psychological Association (APA) and Division 43 of the APA (Society for Family Psychology) have joined together to launch the journal Couple and Family Psychology: Research and Practice (CFP) in 2012. CFP, to be published quarterly, will be a scholarly journal publishing peer-reviewed papers representing the science and practice of family psychology. CFP is intended to be a forum for scholarly dialogue regarding the most important emerging issues in the field, a primary outlet for research particularly as it impacts practice and for papers regarding education, public policy, and the identity of the profession of family psychology.

As the official journal for APA Division 43, CFP will provide a home for the members of the division and those in other fields interested in the most cutting edge issues in family psychology. Unlike other journals in the field, CFP is focused specifically on family psychology as a specialty practice, unique scientific domain, and critical element of psychological knowledge. The journal will seek and publish scholarly manuscripts that make a contribution to the knowledge base of family psychology specifically, and the science and practice of working with individuals, couples and families from a family systems perspective in general.

Mark Stanton, PhD, ABPP, is the Inaugural Editor of CFP. Manuscripts should be submitted electronically via the journal's Manuscript Submission Portal under the Instructions to Authors at http://www.apa.org/pubs/journals/cfp. 